\title{
Flexible and Contextual Cloud Applications in Mobile Learning
}

\author{
https://doi.org/10.3991/ijim.v14i21.18469
}

\author{
Albina Hashimova \\ Azerbaijan State University of Economics, Baku, Azerbaijan \\ Azerbaijan Tourism and Management University, Baku, Azerbaijan \\ Valeriy Prasolov ( $\bowtie)$ \\ Financial University under the Government of the Russian Federation, \\ Moscow, Russia \\ valeriyprasolov@yahoo.com / VIPrasolov@fa.ru \\ Vyacheslav Burlakov \\ Moscow Polytechnic University, Moscow, Russia \\ VNII Center, Moscow, Russia \\ Larisa Semenova \\ Bashkir State Medical University, Ufa, Russia
}

\begin{abstract}
The aim of the article is to study the modern mobile learning system, to understand its advantages and disadvantages, and to determine the relationship between the concepts of digital learning. The goal of the study is to conduct an experiment on the implementation of a flexible mobile application for studying the "macroeconomics" by students of economic specialties and to compare the results obtained with the selected control group. A total of 20 sophomores (10 each from two universities: Sechenov University, Department of Economics and Management; and Azerbaijan State Economic University, Department of Economic Theory) were offered to study the course in macroeconomics using a mobile application during the semester (from September to December 2019). Students were selected from two universities for the scientific objectivity and from the second year of the bachelor's degree, since "macroeconomics" is studied in the early courses, regardless of the further, specific economic direction of the student. Students did not attend lectures and practical classes with a teacher; all training was performed with the help of an application. A control group of the same specialty and year (also 20 people) was selected to confirm or contradict the effectiveness of such a mobile application. The control group students studied "macroeconomics" in the traditional way, namely attending lectures and practical classes with a teacher, during this semester. As a result of the experiment, the study group students liked training with the application. Meanwhile, $70 \%$ of the students would not like to have such training for all disciplines, permanently. But students supported studying using a special mobile app as a supplement to the main format of teaching. During the final examination, held by the traditional method (a written exam answers to 4 open questions and 10 multiple choice questions), the following
\end{abstract}


results were obtained. Students, who were using m-learning, on average, got higher results by 0.2 points, according to the overall assessment, a 5-grade scale, and separately according to the test results more by 2 correct answers than students with the traditional education. Thus, this can be explained since students using mobile app practiced material in a form of game or case, which helped them to immerse themselves more in the problem and to assimilate the material. The results were compared with the research of other scientists.

Keywords - Mobile learning, traditional learning, m-learning, training programs, economics applications, gamification of learning

\section{Introduction}

The modern world is quickly changing and developing so that it is not always possible to keep up with these changes [1]. Technologies that used to seem high and unrealistic are actively used in the everyday life of an ordinary person [2]. It's hard to imagine modern youth without any gadget in their hands. They are always in touch with the world using their smartphone, tablet or even smartwatch. Young people can get any information from any source as quickly as possible. But do they know how to expediently and reasonably dispose of this information? Do they really receive useful information or so-called "digital garbage"?

According to statistical studies from $2020,67 \%$ of the entire population use mobile devices, while over the past year the number of users has increased by 124 million, which is $2.4 \%$ more than last year. It is worth noting that out of 11 minutes of using a smartphone, 10 are spent for mobile apps. Almost $90 \%$ of all time spent in mobile apps is for social networks. According to the statistics on app downloads from 2019, the training apps are on the $10^{\text {th }}$ out of 10 download locations among App Store users. Moreover, such applications do not even make it into the top 10 among Google Play users [3]. This is the modern paradox, as we have a huge number of opportunities for learning and development, but not using them.

Modern schools, universities and educational organizations are already actively using various tools for distant, e-learning and $\mathrm{m}$ - learning to attract their students. The training with a mobile device means not only a smartphone, but also tablets, readers or laptops. That is, all easy-to-move gadgets that are not tied to a specific place, like $\mathrm{PC}$, and, of course, have access to the Internet. The advantage of mobile devices over stationary lies in their constant human maintenance, easy access to the Internet and a small format. The use of mobile devices in teaching makes it continuous, flexible and innovative, which allows improving knowledge and skills anytime and anywhere. Nevertheless, the mobile training programs are not quite popular among the younger generation, despite their maximally simplified access to knowledge [3], since learning via a mobile requires significant self-organization and motivation. Moreover, mobile devices are still not seen as a teaching possibility. Therefore, the main task of all educational institutions is to lead students towards independent learning, search for new knowledge and skills, as well as to develop interactive, flexible and contextual programs to make the learning process more interesting. Such a transition helps a 
person to continue studying and developing independently, after graduation. Therefore, we get professionals in their field. Mobile learning is a tool to achieve such goals [2].

\section{$2 \quad$ Literature Review}

Mobile learning or m-learning is a modern learning technology that uses mobile gadgets to organize the learning process $[1,4]$. Scientists believe that mobile learning is one of the areas of e-learning [4]. In turn, e-learning is defined as a learning system involving the use of electronic means and Internet technologies in the learning process [4]. The concepts of distant learning, e-learning and m-learning are very similar, but still different. M-learning is learning that uses only mobile devices, namely phones, smartphones, laptops, that are easy-to-move gadgets. E-learning uses the full range of electronic devices, regardless of whether they are stationary or mobile. Distant learning is a system that uses a set of tools that allow teacher and student to interact and conduct the learning process at a distance. The most important aspect of distant learning is that the teacher and student must be at a distance, and use different means of communication, regardless of their digital origin [5]. Thus, the distant learning is the broadest concept that includes both e-learning and m-learning. M-learning is the narrowest concept among the given definitions.

The communication with m-learning is not only between the teacher and the student, but also between students, since in the process of work they share their achievements, experiences or failures that can help others.

M-learning has been used for a long time already, since 2003 [6]. This system includes not only special programs, but also social networks and messengers that facilitate the communication process between students and teachers. For example, the teacher can create a special chat in any messenger and add all the students while giving online lectures. Thus, the teacher can easily track the activity of each student, their presence and involvement in work by checking the correspondence after giving a lecture [7]. With the help of gadgets, students can communicate with each other, being at an unlimited distance; photograph or scan information of any format (both paper and electronic); record lectures using a voice recorder; use the phone as a glider or notebook for noting lectures; quickly search the information using a mobile browser [8].

Mobile learning can be used as main learning program, for example, as one of the e-learning options, or in addition to traditional or offline learning. During the traditional learning, the teacher can send students online lectures or materials so that everyone has an access to it and work without any problems. This communication option is a huge advantage when working with a large audience of students. When displaying the same materials on an interactive whiteboard, many students may not see the information or catch-up noting. Nevertheless, to display materials for general viewing, an interactive board, a projector and a computer are required, which is very often a problem for universities, since not every classroom or university has such simple equipment [9]. There is no such problem when sending the same materials to 
each student, since everyone has an electronic gadget and students can always work with the materials at their own temp [10].

Due to Covid-19 pandemic and the transfer of the entire studying to an online format, m-learning, generally, became the basis and rescue for the educational system. Thus, universities or educational organizations, that did not transfer their training system to online, were left "overboard".

Scientists highlight a number of positive aspects of using m-learning:

- Students can study anywhere in the world, whether it is their office or on their way on the subway. This provides an opportunity to learn from foreign teachers just using a gadget. For example, the e-learning has the same advantage, but m-learning further simplifies the process of acquiring new knowledge, since the student is not even tied to the stationary location of a device $[11,12]$.

- Mobile learning allows an almost immediate feedback from the teacher [7].

- Working for group projects, students can have access to one file, allowing everyone to take an active part in the development of the project, change or supplement each other's thoughts [13].

- The use of interesting mobile applications encourages students, who did not show themselves with the traditional learning, to understand the problem independently and deeper [8].

The majority of students do not use apps for learning on their own. They can use such programs or courses only according to the instructions or recommendations of the teacher, that is, in the "voluntary-compulsory" form. This can be explained by the fact that, despite the transfer of learning to a digital format, the very approach to presenting material in cloud apps developed by universities remains the same, formal and theoretical. That is why students generally do not take the initiative to study this or that issue additionally, since even m-learning in most cases is boring and not interesting.

The disadvantages of m-learning include:

- The high cost of good gadgets: Almost every person working in modern conditions has a smartphone, laptop or tablet. Nevertheless, powerful and fast devices that can support any app are very expensive and not everyone can afford it.

- The great eye strains: One of the very negative factors of the m-learning is a great load on vision due to prolonged use of a gadget and constant concentration on it [14].

- Lack of knowledge among teachers of the older generation: Frequently, the most of teaching staff is made up of the older generation, who use traditional teaching methods. Moreover, it is very difficult for them to learn modern technologies. Thus, students know better how to work with this or that app or software [8].

- Therefore, the main task of modern universities is to create competitive educational apps that student would be interested to work with. 


\subsection{Task setting}

The m-learning is already actively used in the business area and is an effective tool for improving work performance and learning new knowledge and skills. Educational institutions use m-learning only partially. The relevance of this topic, and its theoretical and practical significance, led to further research in this area.

The aim of the article is to study the modern mobile learning system, to understand its advantages and disadvantages, and to determine the relationship between the concepts of digital learning. The goal of the study is to conduct an experiment on the implementation of a flexible mobile application for studying the "macroeconomics" by students of economic specialties and to compare the results obtained with the selected control group, as well as with the researches of other scientists.

The relevance of the issue determined the research objectives, namely:

- To identify popular directions and formats of using the m-learning.

- To determine advantages and disadvantages of the m-learning.

- To conduct an experiment on the implementation of a flexible mobile application for studying the "macroeconomics" by students of economic specialties and to compare the results obtained with the selected control group.

- To compare the experience of using m-learning app with other organizations and identify other options for using m-learning.

\section{Methods and Materials}

The educational institutions use some elements of m-learning, such as messengers, social networks, cloud storage. Such tools are auxiliary to the direct learning process. The learning apps are not very popular among students and pupils. To solve this problem, it was proposed to create and develop a special educational mobile app for students of economic specialties.

The Basic Economics App is a contextual and flexible application that aims to enable students to study economic disciplines such as macro or microeconomics in an interesting form using a mobile app. Generally, such basic economic disciplines are taught in a traditional and theoretical manner. No wonder that students do not show much interest in such disciplines. It is possible to solve this problem by creating an interesting app using the gamification method. Gamification can be defined as the use of game elements to solve non-game problems [15]. Thus, all theoretical material on economics is presented in an interesting form of a simulation or a game. Therefore, students do not just read a textbook with a set of "dry" facts and theoretical materials, but practice the same theory in a game form or using cases. Verification of the acquired material is carried out with interactive tests. Students can also communicate with each other via the app, and share their results. This application will help to transmit the learning process into an interesting and flexible format.

To create the application, IT specialists and programmers from a company that develops software and mobile apps in Russia were involved (the name of the company is not mentioned, since it can in any way harm the company's reputation). The 
theoretical content of the app was developed by a team of teachers from the Department of Economic Theory of the Azerbaijan State Economic University. The mobile app and code were written with Front End and XML, and then Java code was written using the android 2.0 studio IDE. Initially, an operating system for a mobile application was either Android or iOS. After studying the statistics on use of operating systems, the Android has been chosen, since it exceeds iOS by about $50 \%$, on average $[16,17]$.

It was planned to develop an application for the studying all basic economic disciplines. The first experimental course was "Macroeconomics". At the current stage of development, the entire application was in fact devoted only to this subject, but in the future, other disciplines could be added in. The user had to download the application from Google Play (since the application was developed only for Androids) and create his own personal account. The following categories were designated in the main menu of the app:

- Lectures on the macroeconomics, divided into 10 separate topics, covering the entire content of the course.

- Practical exercises on each topic, displayed in different forms, e.g., problem solving, case studies, video reviews.

- Multiple choice tests on each topic.

- Chat in which all who studied the course could communicate.

- Technical support, where the user could send his request in case of any problem.

The interface language was Russian, since the application is for students from Russian and Azerbaijani universities. A prerequisite for using the app was an access to the Internet and a smartphone on the Android platform. The immediate limitation of the use of an app was that many students had iOS-based smartphones. To participate in the experiment, they had to get an Android phone. An application must be provided on both operating systems at once in a real development environment.

A group of 20 sophomores (10 each from two universities - Sechenov University, students of the Department of Economics and Management and the Azerbaijan State Economic University, students of the Department of Economic Theory) were offered to study the course in macroeconomics using a mobile application during the semester (from September to December, 4 months) in order to assess the effectiveness of the application. Students were selected from two universities for the scientific objectivity and from the second year of the bachelor's degree, since "macroeconomics" is studied in the early courses, regardless of the further, specific economic direction of the student. The participants did not attend lectures and practical classes with a teacher; all training was performed with the help of an application. Nevertheless, students could always ask their teacher any question. The curators of this experiment were two teachers from each university, who moderate and supervise the entire learning process of their group of 10 people. They monitored the timely studying of topics, practical classes and test results. All participants in the experiment (20 students and two teachers) were consulted by IT specialists regarding the technical part the application before the experiment. A control group of the same specialty and year (also 20 people) was selected to confirm or contradict the effectiveness of such a mobile application. 
The control group students studied "macroeconomics" in the traditional way, namely attending lectures and practical classes with a teacher, during this semester. The material in the two experimental groups was the same, and the main difference was in the form of its presentation.

\section{$4 \quad$ Results}

The use of m-learning in higher education is not a common approach as a main learning method. Mobile devices, in turn, are developing so quickly that they are already getting over some PC by temps of development and capacities. The mobile apps in universities can be used additionally to traditional education, which has not changed for many years. Nevertheless, to implement m-learning as a main, firstly, it's better to apply the synergy of traditional and innovative approaches. Thus, an experiment of implementing a mobile educational application for studying the discipline of "macroeconomics" is relevant.

The experiment of using the contextual app in teaching "macroeconomics", involving 20 students from two universities, and 20 students as a control group, showed certain results. A group of students studied the discipline only using the developed mobile application for 4 months. The course included one practical and one theoretical lesson per week ( 1 astronomical hour). The student had to pass a test, after each topic, determining the final grade. Thus, students had to fully master the material in 4 months. After the experiment, students and the teacher were asked questions, the results of which are summarized in Table 1.

Table 1. Results of the survey of experiment participants

\begin{tabular}{|c|c|}
\hline Question & Answer \\
\hline \multicolumn{2}{|l|}{ For students } \\
\hline Was the application difficult to understand? & $\begin{array}{l}\text { Yes }-10 \% \\
\text { No }-90 \%\end{array}$ \\
\hline Do you think what did you learn from such training? & $\begin{array}{l}\text { Yes }-10 \% \\
\text { No }-90 \%\end{array}$ \\
\hline Was such training interesting? & $\begin{array}{l}\text { Yes }-10 \% \\
\text { No }-90 \%\end{array}$ \\
\hline $\begin{array}{l}\text { Do you think which training model is more effective: traditional or learning using } \\
\text { the app? }\end{array}$ & $\begin{array}{l}\text { Yes }-60 \% \\
\text { No }-40 \% \\
\end{array}$ \\
\hline Would you like to have learning model permanently for studying all disciplines? & \begin{tabular}{|l|} 
Yes $-30 \%$ \\
No $-70 \%$ \\
\end{tabular} \\
\hline $\begin{array}{l}\text { Mention reasons why you would not like to have m-learning as the main one (if the } \\
\text { answer to the previous question was "Yes", please skip this question)? }\end{array}$ & $\begin{array}{l}50 \% \text { - lack of "live } \\
\text { communication" } \\
40 \% \text { - great eye strains } \\
10 \% \text { - other }\end{array}$ \\
\hline $\begin{array}{l}\text { Would you like to keep this learning model as an addition to the main for some } \\
\text { disciplines? }\end{array}$ & \begin{tabular}{|l|} 
Yes $-80 \%$ \\
No $-20 \%$ \\
\end{tabular} \\
\hline \multicolumn{2}{|l|}{ For curators } \\
\hline How long did it take you to prepare for a traditional lesson? & About three hours \\
\hline How long did it take you to prepare for a lesson using the app? & About 30 minutes \\
\hline How long did it take you to check the lesson results in the traditional learning? & About 30 minutes \\
\hline How long did it take you to check the results and monitor students using the app? & About 10 minutes \\
\hline
\end{tabular}


According to survey results, most students liked training with the application. Meanwhile, $70 \%$ of the students would not like to have such training for all disciplines, permanently. But students supported studying using a special mobile app as a supplement to the main format of teaching. If analyze the results on the part of the teachers, a significant saving of time for preparing for classes (the time is almost 6 times reduced) and for assessing the flow results of students (decreased in the same rate) had been noticed.

Nevertheless, the main goal of any innovation is to improve efficiency and effectiveness. That is the final results of the exam. To assess the effectiveness of m-learning app, the results of students from study and control groups should be compered.

Regardless of the form of learning, all students passed the final exam in "macroeconomics" in a traditional way (a written exam - answers to 4 open questions and 10 multiple choice questions) in the classroom without using any additional materials. The results are shown in Table 2.

Table 2. Exam results

\begin{tabular}{|c|c|c|c|c|}
\hline \multirow[b]{2}{*}{ Student } & \multicolumn{2}{|c|}{ The study group } & \multicolumn{2}{|c|}{ The control group } \\
\hline & $\begin{array}{l}\text { Final exam results } \\
\text { (a 5-grade scale) }\end{array}$ & $\begin{array}{c}\text { Multiple choice test } \\
\text { results (number of } \\
\text { correct answers) }\end{array}$ & Final exam results & $\begin{array}{c}\text { Multiple choice test } \\
\text { results }\end{array}$ \\
\hline 1 & 4.2 & 6 & 3.5 & 6 \\
\hline 2 & 4.6 & 8 & 4.3 & 5 \\
\hline 3 & 4.2 & 7 & 4 & 6 \\
\hline 4 & 5 & 10 & 3.7 & 6 \\
\hline 5 & 4.8 & 10 & 4.8 & 6 \\
\hline 6 & 3.8 & 4 & 3.8 & 4 \\
\hline 7 & 3.5 & 9 & 4.5 & 7 \\
\hline 8 & 4.5 & 8 & 3.8 & 6 \\
\hline 9 & 4.2 & 7 & 4.2 & 5 \\
\hline 10 & 4 & 6 & 4 & 6 \\
\hline 11 & 5 & 9 & 3.6 & 3 \\
\hline 12 & 5 & 8 & 4.9 & 8 \\
\hline 13 & 3.7 & 10 & 3.7 & 10 \\
\hline 14 & 3.2 & 6 & 3.2 & 6 \\
\hline 15 & 4 & 9 & 4 & 9 \\
\hline 16 & 3.8 & 10 & 3.7 & 4 \\
\hline 17 & 4 & 6 & 3.7 & 5 \\
\hline 18 & 3.2 & 8 & 3.2 & 4 \\
\hline 19 & 4.5 & 8 & 4.4 & 8 \\
\hline 20 & 3.5 & 10 & 3.5 & 10 \\
\hline Average & 4.1 & 8 & 3.9 & 6 \\
\hline
\end{tabular}

Based on the exam results, the following diagram was developed (Fig. 1): 


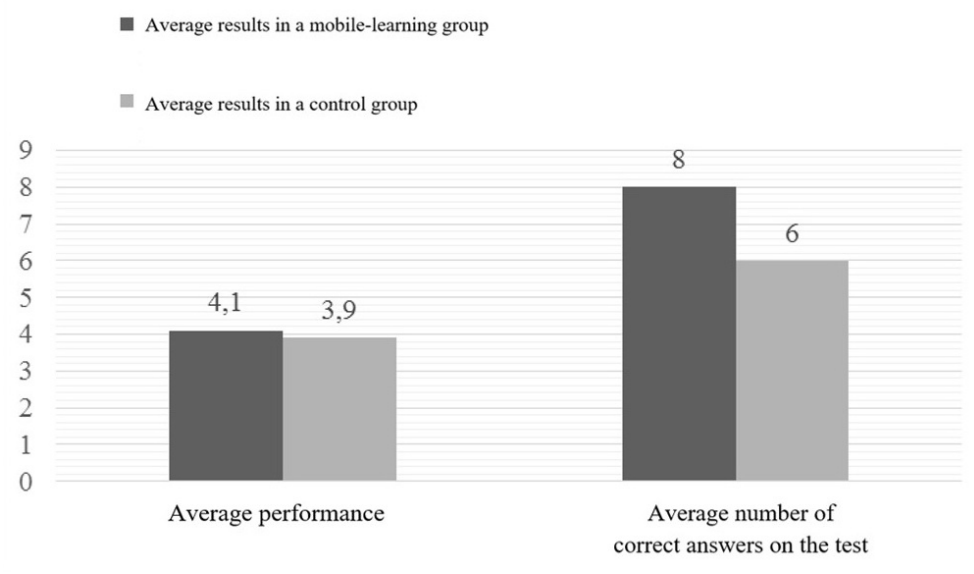

Fig. 1. The results of students in "macroeconomics" (created by the authors)

According to Tab. 2 and the diagram, students using a mobile application passed the exam more successfully than students with a traditional approach. Thus, this can be explained since students using mobile app practiced material in a form of game or case, which helped them to immerse themselves more in the problem and to assimilate the material. Nevertheless, students would not like to have m-learning app as main form of training. Thus, both methods should be used in interaction, to provide higher final results.

Therefore, the hypothesis on the synergy of using traditional approaches along with mobile applications has been confirmed. Then, student performance will increase significantly. Furthermore, the negative aspects of m-learning highlighted by other scientists, e.g., great eye strains, had been also confirmed.

\section{Discussion}

The mobile cloud applications are already actively used in both higher education and business environments. The business area still uses an innovative approach to learning more actively and implements it in daily life.

Universities, in turn, use mobile applications both for the direct learning process and for its regulation and organization (E.g. The main operational activities and service processes). These can be programs for assessing student progress, the so-called electronic journals, messengers, specifically created for communication between students and teachers of a particular university, cloud storage, etc. For example, electronic journals are actively used in post-Soviet higher educational institutions. Such software greatly simplifies the process of tracking progress, making it mobile and flexible, since students can monitor their results from any mobile device. Examples of universities that use such mobile applications can be Kazan Federal University [18], St. Petersburg State University [19] or Kiev National Economic University [20]. 
Considering mobile apps as a direct tool for learning, the most common are such cloud programs as Microsoft Learning Content Development System, 1C: ELearning, Course Designer, Moodle. With their help, e-learning programs, whole courses or individual lessons are created. There is also a whole system of programs that are aimed at developing electronic textbooks or books. The most common are Apple‘s i-Books Author, Google's Course Builder, or Samsung's Magic Info IPremium Author. Such programs help to easily create electronic textbooks for students in the format of diagrams, graphs or tables. They also help to transmit an ordinary printed textbook into a mobile format [6].

Dozens of different contextual applications for m-learning have been developed that specialize in different areas of life. A huge number of applications are designed for schoolchildren. Students can learn physics through a virtual textbook with additional reality; a special app focusing on all mathematical actions is offered for mastering math. The tasks become more difficult with each new level. The application "science - microcosm" will help the student to understand any objects in the universe, to explore neurons or protons [21]. Considering the most common version of m-learning for adults, the learning of foreign languages is the most popular. This is due to the fact that foreign languages, in particular English, are a necessary for a person of almost any specialty. Therefore, such contextual learning is the most popular both in the business and educational environment.

One of the widespread m-learning apps for learning foreign languages is LinguaLeo [22], where student practice writing sentences or phrases on a given topic, learns new words. The learning is performed in a playful way, using the gamification, which makes it easier and better to perceive new material.

The experience of learning English with m-learning was also described in various studies by foreign scientists from Malaysia and Nigeria $[23,24]$. Scientists note that the use of mobile applications additionally to main learning model makes the learning process continuous, increases the qualification level and the quality of mastering the material.

Scientists in Malaysia and Nigeria define mobile learning only as an additional (as in our experiment), while Swedish scientists recognize mobile learning as the main tool and means of increasing the effectiveness of the learning process. In their opinion, m-learning will become the main approach for teaching students of different specialties in the future [25].

Comparing the experiment on the implementation of a special contextual application for training economists in a university, it was figured out that similar methods for the implementation of apps are already used all over the world. The differences lie precisely in the direction of the application. The proposed flexible approach using a mobile app in learning can be an excellent solution to increase the efficiency of teaching students of economic specialties. 


\section{Conclusion}

The mobile apps are still not perceived by society as a full-fledged learning. Majority of students do not use learning apps on their own. Therefore, m-learning is not very popular among higher education students. It is possible to solve this problem by creating an app, using gamification, for studying "macroeconomics" for students of economics. The experiment involved 40 students and 2 curators. Half of the students studied using a mobile application, and the other half studied with traditional learning. As a result of the experiment, the study group students liked training with the application. Meanwhile, $70 \%$ of the students would not like to have such training for all disciplines, permanently. But students supported studying using a special mobile app as a supplement to the main format of teaching. The final examination was held in the traditional way (a written exam - answers to 4 open questions and 10 multiple choice questions), the following results were obtained. Students, who were using m-learning, on average, got higher results by 0.2 points, according to the overall assessment, a 5grade scale, and separately according to the test results more by 2 correct answers than students with the traditional education. Thus, this can be explained since students using mobile app practiced material in a form of game or case, which helped them to immerse themselves more in the problem and to assimilate the material.

Comparing the experiment on the implementation of a special contextual application for training economists in a university, it was figured out that similar methods for the implementation of apps are already used all over the world. The differences between applications lie precisely in the teaching materials (from learning English to mastering math).

A promising search area for further research is the display of new experience in using contextual mobile applications, since it is actively developing and the introduction of new experience can be very interesting for both business and scientific environment.

\section{$7 \quad$ References}

[1] Cherkasov A.A., Bratanovskii S.N., Koroleva L.A., Zimovets L.G. (2019). Development of School Education in the Vologda Governorate (1725-1917). Part 1. European Journal of Contemporary Education, 8(1): 208-214. https://doi.org/10.13187/ejced.2019.1.208

[2] Cherkasov A.A., Bratanovskii S.N., Koroleva L.A., Zimovets L.G. (2019). Development of the School Education System in the Province of Vologda (1725-1917). Part 2. European Journal of Contemporary Education, 8(2): 418-424. https://doi.org/10.13187/ejced.2019.2 $\underline{.418}$

[3] Sergeeva, Y. (2020). All Internet statistics for 2020 - numbers and trends in the world and in Russia. Web Canape. https://www.web-canape.ru/business/internet-2020-globalnaya-sta tistika-i-trendy

[4] Liu, Z. Y., Spitsyna, N., Zubanova, S., \& Vekilova, A. (2020). Using Internet Resources for Remote Language Learning. International Journal of Emerging Technologies in Learning (iJET), 15(13): 22-33. https://doi.org/10.3991/ijet.v15i13.14653 
[5] Zubkova, M.A., Fominykh, N.Iu., Baranova, E.N., Abbasova, L.Il., Pirozhkova, A.O., Bubenchikova, A.V., Maigeldieva, Sh.M. (2019). Approaches to the future engineer's foreign communicative culture formation. Humanities \& Social Sciences Reviews, 7(4): 781-786.

[6] Makarchuk T.A., Minakov V.F., Artem'ev A.V. (2013). Mobile learning on the basis of cloud services. In International Association for Development of the Information Society (IADIS) International Conference on E-Learning, Lisbon, Portugal, Jul 20-22, 2017, pp. $175-178$.

[7] Kliment'ev, D.D., Kliment'eva, V.V. (2018). Affordable mobile apps in education: free, interesting, easy and effective. Scholarly notes. Electronic scientific journal of Kursk State University, 1(45): 1-8.

[8] Luzgina, V.B., Stahovskaja, Zh.A. (2016). Experience in using mobile technologies in the educational environment. Educational technology and society, 1: 1-10.

[9] Fominykh, N., Barsova, O., Zarudnaya, M., \& Kolomiytseva, N. (2016). Approaches to prospective economist's professional foreign language training in computer orientated language learning environment. International Journal of Environmental and Science Education, 11(18): 12067-12083.

[10] Zhilina A.I., Chepurenko G.P., Jur'eva D.V. (2019). Mobile learning as a pedagogical innovation in the knowledge management system. Bulletin of the Leningrad State University. AS Pushkin, 2: 132-145.

[11] Blazhko, O.O., Kostunets, T.A. (2017). Modern trends in the development of distant learning in the university. In Distant learning as a modern educational technology. VTEI KNTEU, Vinnytsia, pp. 10-12.

[12] Costley, K.C. (2014). The Positive Effects of Technology on Teaching and Student Learning. Online Submission. https://files.eric.ed.gov/fulltext/ED554557.pdf

[13] Rimale, Z., El Habib, B., Tragha, A., El Guemmat, K. (2016). Survey on the use of the mobile learning based on mobile cloud computing. International Journal of Interactive Mobile Technologies, 10(3): 35-41. https://doi.org/10.3991/ijim.v10i3.5672

[14] Vlasenko, I.H. (2017). The introduction of distant learning as the modern requirement. In Distant learning as a modern educational technology. VTEI KNTEU, Vinnytsia, pp. 12-14.

[15] Lee, J., Hammer, J. (2011). Gamification in Education: What, How, Why Bother? Academic Exchange Quarterly, 15(2):1-5.

[16] Hill, S. (2020). Android vs. iOS: Which smartphone platform is the best? Digital Trends. https://www.digitaltrends.com/mobile/android-vs-ios/

[17] Stat Counter Mobile Operating System Market Share Worldwide. https://gs.statcounter. com/os-market-share/mobile/worldwide

[18] Kazan Federal University, Official website. https://students.kpfu.ru/learning/distance-lear ning

[19] St. Petersburg State University. Official website. https://spbu.ru/studentam/obuchenie

[20] Kiev National Economic University. Official website. http://dekanat.kneu.edu.ua/cgi-bin/k af.cgi? $\mathrm{n}=999 \& \mathrm{t}=98$

[21] Medved'eva N.P. (2016). Mobile learning as a new technology in education. In VIII International Pedagogical Forum. https://www.institute-of-education.com/methodlib/1844/153 $\underline{712}$

[22] LinguaLeo. Official website. https://lingualeo.com/ru/

[23] Khan, R., Radzuan, N., Alkhunaizan, A., Mustafa, G., Khan, I. (2019). The Efficacy of MALL Instruction in Business English Learning. International Journal of Interactive Mobile Technologies, 13(8): 60-73. https://doi.org/10.3991/ijim.v13i08.9562 
[24] Oyelere, S.S., Suhonen, J., Sutinen, E. (2016). M-Learning: A new paradigm of learning ICT in Nigeria. International Journal of Interactive Mobile Technologies, 10(1): 35-44. https://doi.org/10.3991/ijim.v10i1.4872

[25] Liu, P.L., Chen, C.J., Chang, Y.J. (2010). Effects of a computer-assisted concept mapping learning strategy on EFL college students' English reading comprehension. Computers \& Education, 54(2): 436-445. https://doi.org/10.1016/i.compedu.2009.08.027

\section{Authors}

Hashimova Albina is a Candidate for a $\mathrm{PhD}$ degree of the Azerbaijan State University of Economics (UNEC), Baku, Azerbaijan. She is lecturer of the Azerbaijan Tourism and Management University, Baku, Azerbaijan.

Prasolov Valeriy Ivanovich is a PhD of Political Sciences, Associate Professor of the Department of Risk Analysis and Economic Security, Financial University under the Government of the Russian Federation, Moscow, Russia. Email: valeriyprasolov@yahoo.com, VIPrasolov@fa.ru

Burlakov Vyacheslav Viktorovich is a PhD of Economic Sciences, Professor of the Department of Economics and Organization, Moscow Polytechnic University, Moscow, Russia; VNII “Center”, Moscow, Russia.

Semenova Larisa Vasilevna is a $\mathrm{PhD}$ of Economic Sciences, Assistant Professor of the Department of Philosophy, Bashkir State Medical University of the Ministry of Health of the Russian Federation, Ufa, Russia.

Article submitted 2020-09-12. Resubmitted 2020-10-26. Final acceptance 2020-10-26. Final version published as submitted by the authors. 